\title{
EVALUATION OF LEARNING AND MEMORY IN RATS THROUGH ELEVATED PLUS MAZE MODEL Dr. Manju Gari ${ }^{1}$, Dr. Manisha Varshney ${ }^{1}$ \\ ${ }^{1}$ Department of Pharmacology and Therapeutics, RIMS, Ranchi, India
}

Article Info: Received 15 February 2020; Accepted 28 March 2020

DOI: https://doi.org/10.32553/jbpr.v9i2.727

Address for Correspondence: Dr. Manisha Varshney

Conflict of interest statement: No conflict of interest

ABSTRACT:

The understanding of dementia has evolved over 2500 years, from a vague notion of unavoidable age-related memory loss, to a present understanding of its characteristic clinical and pathologic features. Alzheimer disease (AD) symptoms include decline in cognitive function and it is most common form of dementia. In this pharmacological study two drugs Metformin and Bacopa monnieri have been tested to evaluate their efficacy in treatment of AD using Elevated Plus Maze model by evaluating effect of these drugs on learning and memory in rats. The results shown during experiments are promising by both these drugs in improvement of learning and memory in rats, and therefore could be the potential therapy in treatment of $A D$ as well.

Keywords: Elevated Plus Maze, Alzheimer disease, Memory, Transfer Latency

\section{Introduction}

Learning has been defined as changes in the behaviour of an organism that result from regularities in the environment of the organism ${ }^{1}$. Darwin's theory of evolution stated that the basis of evolution is adaptation to the environment. Features that improve with adaptation are more likely to be passed onto next generation. Therefore, learning can also be seen as adaptation of an individual organism to its environment during the lifetime of the individual. Memory has been defined as the ability to use our past experiences to determine our future path. Memory refers to the dynamic mechanisms associated with storing, retaining, and retrieving information about past experience ${ }^{2,3}$.

Dementia, syndrome of a chronic or progressive nature which is characterised by loss of memory functions (i.e. the ability to process thought) beyond what usually is expected from normal ageing. It mainly affects memory but also affects thinking, orientation, comprehension, calculation, learning capacity, language, and judgement ${ }^{4,5}$. Although dementia mainly affects older people but it has never been considered as a normal part of ageing. Worldwide, around 50 million people have dementia, and there are nearly 10 million new cases every year ${ }^{6}$. Dementia has become one of the major causes of disability among older people worldwide. Dementia not only affects the people who suffer from it but also affect their care takers impacting their psychological and physical health along with social and economic status. There are many different forms of dementia out of which the most common form is Alzheimer disease contributing to around $60-70 \%$ of cases. People suffering with dementia are projected to reach about 82 million in 2030 and 152 million in $2050^{6}$.

Mild Cognitive Impairment $(\mathrm{MCl})$ is a condition in which an individual has mild but measurable changes in thinking capacities which do not affect the person's ability to carry out daily activities but these cognitive changes are noticeable to the person affected and to family members and friends. Approximately $15-20 \%$ of people aged 65 or older have $\mathrm{MCl}^{7}$. Alzheimer's or other dementias tend to develop more likely in people suffering from $\mathrm{MCl}$, especially $\mathrm{MCl}$ involving memory problems.

There are only subtle differences between typical agerelated cognitive changes and signs of Alzheimer's with the most common initial symptom being gradually worsening ability to remember new information. This happens because the first neurons which are damaged and destroyed are usually in cortical and hippocampal regions involved in forming new memories. Individuals start experiencing other difficulties, including neurobehavioral symptoms such as agitation, delusions and sleeplessness as neurons in other parts of the brain are damaged and destroyed.

Recently, scientists have put their efforts in establishing role of metformin in the treatment of Alzheimer's disease (AD), amnestic mild cognitive impairment, Parkinson's disease and various other 
neurodegenerative diseases. Many studies have been done on plants which belong to Scrophulariaceae family, mainly Bacopa monnieri and its polyphenolic compounds, bacosides to establish their neuroprotective properties. Nutraceuticals have an effect on various neurodegenerative diseases as they modulate signaling pathways ${ }^{8}$.

Therefore the test drugs, Metformin and Bacopa monnieri have been used in this pharmacological study to evaluate their potential and study their efficacy in drug repositioning in prevention of Alzheimer's disease. Therefore, these drugs were tested to study their effects in learning and memory in scopolamine induced dementia in albino rats using Elevated Plus Maze model. To assess and evaluate learning and memory in laboratory animals mazes are simple but effective tools and have been used traditionally.

Elevated Plus Maze was introduced by Pellow (1985) with rats and by Lister (1987) with mice ${ }^{9,10}$. It consists of two opposite closed arms, crossed with two open arms of the same dimensions with $40 \mathrm{~cm}$ high walls. The arms are connected with a central square $(10 \mathrm{~cm} \times 10 \mathrm{~cm})$. Rats are placed individually facing away from the central square, at one end of an open arm. Time taken for the rat to move from the open arm and enter into one of the closed arms is recorded which is termed as "initial transfer latency" (ITL). Animals are made to explore the maze for 30 seconds after recording the transfer latency. "Retention transfer latency" (RTL) is recorded after 24 hours by placing the rats similarly on the open arm of the Elevated Plus Maze.

\section{Materials and Methods}

This study was approved by the Institutional Animal Ethics Committee (IAEC) and carried out in the Department of Pharmacology, RIMS, Ranchi, a tertiary care hospital. The present study consisted of healthy Male Wistar albino rats weighing between 150-200 grams. The animals were kept in groups, in clean and dry cages. The animals were acclimatized for 7 days to the laboratory conditions before behavioural experiments. All the cages were appropriately labelled. Animals in each individual cage were also labelled separately and colour coding was done with the help of a permanent marker. These rats were divided into five different groups, five animals in each group. The groups were as shown in table below and surface area of rats was used to determine drug dosage. Metformin, B. monnieri and Rivastigmine were freshly prepared daily and given orally using animal feeding tube (gavage tube) daily. Scopolamine was given intraperitoneally $30 \mathrm{~min}$ before the experiment. Elevated Plus maze model was used to assess the memory enhancing effect of drugs Metformin and Bacopa and compared with standard drug
Rivastigmine while Scopolamine was used to produce amnesia. A total of twenty five $(\mathrm{N}=25)$ rats were used, Five rats in each of Control, Metformin plus scopolamine, Bacopa plus scopolamine, Scopolamine alone and Rivastigmine plus scopolamine groups.

Table 1: Different groups with their respective drugs and doses

\begin{tabular}{llll}
\hline GROUP & NO. OF RATS & DRUGS & DOSE \\
\hline GROUP I & 5 & $1 \%$ Gum acacia & $10 \mathrm{ml} / \mathrm{kg}$ body wt. \\
\hline GROUP II & 5 & Scopolamine & $1 \mathrm{mg} / \mathrm{kg}$ body wt. \\
\hline GROUP III & 5 & Metformin & $100 \mathrm{mg} / \mathrm{kg}$ body wt. \\
\hline GROUP IV & 5 & B. monnieri & $100 \mathrm{mg} / \mathrm{kg}$ body wt. \\
\hline GROUP V & 5 & Rivastigmine & $0.5 \mathrm{mg} / \mathrm{kg}$ body wt. \\
\hline
\end{tabular}

In this pharmacological experimental study of 16 days, the elevated plus maze consist of two open $(50 \times 10 \mathrm{~cm})$ and two closed arms $(50 \times 10 \times 40 \mathrm{~cm})$ facing each other with an open roof. The entire maze is elevated to a height of $50 \mathrm{~cm}$ above the ground. The animals are placed individually at the end of either of the open arms and the time animal takes to move from open to enclosed arm (initial transfer latency) is noted initially. Transfer latency is the time elapsed between the time the animal is placed in the open arm and the time at which all its legs have crossed and entered into the enclosed arm. This transfer latency time is markedly shortened if the animal had previously experienced entering the open arms, and this shortened transfer latency time has been shown to be related to memory processes (Retention Latency).

Initial transfer latency was observed on $15^{\text {th }}$ day. Retention Latency (Memory) was tested on $16^{\text {th }}$ day of the experiment that is after $24 \mathrm{hrs}$ of recording of Initial Transfer Latency. One way Analysis Of Variance (ANOVA) test was used for statistical analysis of data to compare the effect of drugs on different groups. For post-hoc analysis of significant overall differences, Tukey's HSD test was used.

\section{Results}

The comparison of the mean and SD (standard deviation) between different groups of rats as obtained from experiment for Elevated Plus Maze test after administering the corresponding drugs (as mentioned in Table 1 above) is shown in Table 2 below for all the groups. The time mentioned in Table 2 corresponding to Day 15 is ITL (Initial transfer latency) time and corresponding to Day 16 is RL (Retention latency) time in seconds. Figure 1 shows comparison of ITL and RL mean time in seconds between all groups. 
Table 2: Comparison of Mean and SD (standard deviation) of ITL time (Day 15) and RL time (Day 16) in seconds for all the groups in Elevated plus Maze test

\begin{tabular}{|c|c|c|c|c|c|}
\hline & $\begin{array}{l}\text { Group 1 } \\
\text { (Control) }\end{array}$ & $\begin{array}{l}\text { Group 2 } \\
\text { (Scopolamine) }\end{array}$ & $\begin{array}{l}\text { Group } 3 \\
\text { (Metformin \& } \\
\text { Scopolamine) }\end{array}$ & $\begin{array}{l}\text { Group } 4 \text { (Bacopa } \\
\text { monnieri \& } \\
\text { Scopolamine) }\end{array}$ & $\begin{array}{l}\text { Group 5 } \\
\text { (Rivastigmine \& } \\
\text { Scopolamine) }\end{array}$ \\
\hline & Mean \pm SD & Mean \pm SD & Mean \pm SD & Mean \pm SD & Mean \pm SD \\
\hline$\stackrel{\text { ก }}{\underset{\pi}{\pi}}$ & $41.51 \pm 1.76$ & $57.09 \pm 6.56$ & $45.91 \pm 5.32$ & $47.63 \pm 5.76$ & $43.52 \pm 2.98$ \\
\hline$\stackrel{0}{7}$ & $18.42 \pm 1.65$ & $69.22 \pm 8.29$ & $23.51 \pm 3.64$ & $25.07 \pm 2.79$ & $21.45 \pm 2.70$ \\
\hline
\end{tabular}

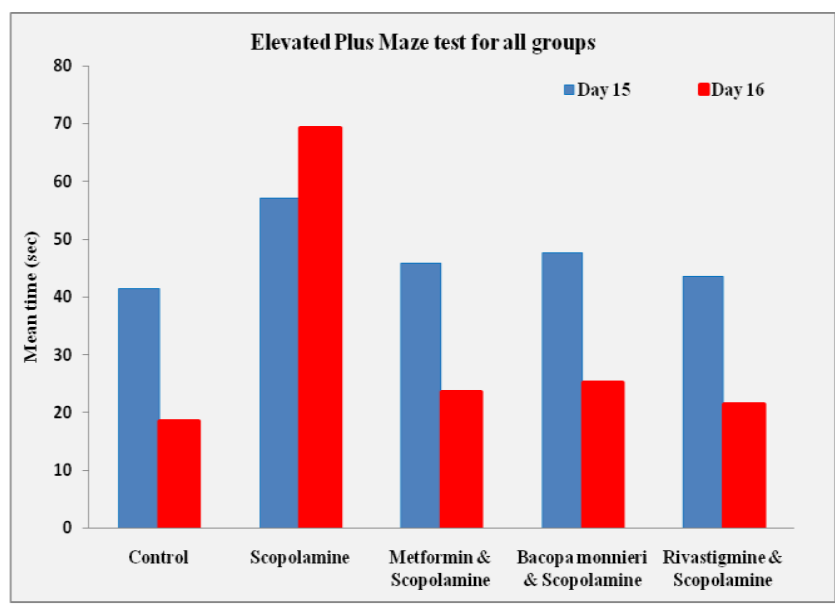

Figure 1: Shows comparison of ITL and RL mean time in seconds between all groups.

Scopolamine treated rats showed significantly higher transfer latencies compared to the control group during both the acquisition (day 15) and retention (day 16) testing sessions. Present study revealed that exposure to Scopolamine, which was used as an amnesic agent, impaired the learning and memory processing activities in rodents, i.e. there was delayed learning in this group which was measured by an increased initial transfer (ITL) latency time which was $57.09 \mathrm{sec}$ on day 15, and on 16th day Retention latency time (RL)was $69.22 \mathrm{sec}$. When this was compared to Control (group 1), ITL was $41.51 \mathrm{sec}$ and on $16^{\text {th }}$ day Retention latency time (RL) was $18.42 \mathrm{sec}$.

Metformin treated animals (group 3), Bacopa treated animals (group 4) and Rivastigmine treated animals (group 5) showed an improvement in learning of task in Elevated Plus Maze Test which is evident by decrease in mean time from day 15 to day 16 for all three when compared to Scopolamine (group 2).

\section{Discussion}

The present study was designed to evaluate the effect of drugs Metformin and Bacopa for its learning and memory enhancing effect and it was compared for its effect with standard drug Rivastigmine while Scopolamine was used to produce dementia. The data shows that there was a significant impairment of learning in Scopolamine (group 2) treated group, which was significant on both the days 15 and 16. Scopolamine is used to induce Alzheimer's type dementia for screening of potential cognition enhancing agents as a pharmacological model of memory dysfunction in animals. Scopolamine disrupts the integrity of cholinergic neurotransmission. These observations were quite similar to the previous studies done by Milind Parle et al., on Reversal of Memory Deficits in Rats. The Initial Transfer latency (ITL) in control group was observed to be $46.8 \mathrm{sec}$ and RL was $26.6 \mathrm{sec}$. ITL in Scopolamine treated group was $48.4 \mathrm{sec}$ and RL was $64.2 \sec ^{11}$.

Metformin activates adenosine monophosphate activated protein kinase (AMPK), which modulates long term potentiation and also helps in memory formation. Treatment with metformin is associated with attenuation of neuro-inflammation, as evidenced by decreasing Tumor Necrosis Factor (TNF- $\alpha$ ) in brain tissues. TNF- $\alpha$, a proinflammatory cytokine, is upregulated in $A D$ and plays a role in pathogenesis of cognitive impairment ${ }^{12}$.

Study conducted by Prabhat Upadhyay et al (2018) also showed reversal of amnesia produced by scopolamine $\left(2 \mathrm{mg} / \mathrm{kg} /\right.$ day) on administration of $\mathrm{B}$. monnieri extract ${ }^{13}$. The Bacopa monnieri extract enhanced acetylcholine levels in the frontal cortex and hippocampus and also reduced AChE activity in the hippocampus of scopolamine treated rats indicating its positive effects on learning and memory are partially mediated by the cholinergic system.

Consistent with previous study done by Thippeswamy et al., (2013) has shown that Bacopa monnieri enhances memory and learning skills and its phytoconstituents, bacoside $\mathrm{A}$ and bacoside $\mathrm{B}$, are considered to be responsible for its beneficial effect in improving memory and learning deficits ${ }^{14}$.

Rivastigmine is a parasympathomimetic and a reversible cholinesterase inhibitor. It leads to an increased concentration of acetylcholine at cholinergic synapses. It is one of the approved anti-dementia drugs. The study showed that in the EPM task, animals treated with Rivastigmine and B. monnieri showed better acquisition and retention latencies compared to the groups treated with amnesic agent.

Rats exposure to scopolamine caused a significant increase in the activity of enzyme, AChE which is involved in the metabolism of acetylcholine in hippocampus. 
Comparison between Rivastigmine + Scopolamine (group 5) and Metformin + Scopolamine (group 3) and comparison between Rivastigmine + Scopolamine (group 5) and Bacopa monnieri + Scopolamine (group 4), shows that in all the groups an improvement in learning and memory has occurred. But no statistically significant difference was found among them i.e., it can be concluded that both the test drugs are identical in reversing amnesia produced by scopolamine. After analysing the results it can also be concluded that Rivastigmine pretreated rats, a standard drug approved for the treatment of dementia, had better learning of task than Metformin and Bacopa monnieri treated rats.

\section{Conclusion}

The results of this study concurs with findings from previous human and animal studies using Elevated Plus Maze test and concludes that Metformin and Bacopa monnieri have markedly improved learning and memory in rats as compared to control but Rivastigmine caused more improvement when compared to Metformin and Bacopa monnieri. The beneficial effect on memory observed may be due to previously demonstrated antioxidant, cholinergic effect and by activating AMPactivated protein kinase (AMPK), which modulates long term potentiation and memory formation.

A worthwhile extension of the current study could be conducted to assess whether these findings are replicable in other models of learning and memory. So, further studies using Metformin and Bacopa monnieri should be carried out for evaluating the memoryenhancing effects of these drugs. Adopting the methods for observing the changes in the brain by Chemical methods like Microdialysis of Acetylcholine release at synapses, CT scan, and functional MRI, might be helpful in such type of study in a more sensitive and specific way.

\section{References}

1. Houwer J, Barnes-Holmes D, Moors A. What is learning? On the nature and merits of a functional definition of learning. Psychonomic Bulletin \& Review 2013; 20(4): 631-642.

2. Bjorklund DF, Schneider W, Hernandez Blasi C. Memory. In J. Levin (Section Ed.) Encyclopedia of cognitive sciences, Vol. 2, 1059-1065. London: Macmillan; 2003.

3. Crowder RG. Principles of learning and memory. Oxford, England: Lawrence Erlbaum; 1976.

4. Dening $T$, Sandilyan MB. Dementia: definitions and types. Nurs. Stand. 2015; 29: 37-42.

5. Wahl $D$ et al. Aging, Lifestyle and Dementia. Neurobiology of Disease 2019; 130: 104481.

6. http://www.who.int

7. Roberts R, Knopman DS. Classification and epidemiology of $\mathrm{MCl}$. Clin Geriatr Med 2013; 29:753-772.

8. Aimi Set al. Bacopa monnieri, a Neuroprotective Lead in Alzheimer Disease: A Review on Its Properties, Mechanisms of Action, and Preclinical and Clinical Studies. Drug Target Insights 2019; 13: 1-13.

9. Pellow S, Chopin P, File SE, Briley M. Validation of open: closed arm entries in an elevated plus-maze as a measure of anxiety in the rat. J. Neurosci. Methods 1985; 14: 149-167.

10. Lister RG. The use of a plus-maze to measure anxiety in the mouse. Psychopharmacology 1987; 92: 180-185.

11. Parle $M$, Singh N. Reversal of Memory Deficits by Atorvastatin and Simvastatin in Rats. J stage, Yakugaku Zasshi 2007; 127(7): 1125-1137.

12. Lee SY et al. Probing the mechanical properties of TNF-alpha stimulated endothelial cell with atomic force microscopy. Int J Nanomedicine 2011; 6: 179-195.

13. Upadhyay $P$ et al. Revalidation of the neuroprotective effects of a United States patented polyherbal formulation on scopolamine induced learning and memory impairment in rats. Biomed. Pharmacother. 2018; 97: 1046-1052.

14. Thippeswamy AH, Rafiq $M$, Viswantha $G L$, Kavya $K J$, Anturlikar SD, Patki PS. Evaluation of Bacopa monniera for its synergistic activity with rivastigmine in reversing aluminuminduced memory loss and learning deficit in rats. J Acu-punct Meridian Study 2013; 6: 208-213. 